\title{
THỰC TRANG VÀ MộT SỐ YẾU TỐ LIÊN QUAN ĐẾN SỬ DỤNG RƯợU BIA Ở NAM SINH VIÊNN Y ĐA KHOA TẠI TRƯỜNG ĐẠI HỌC Y DƯợ'C THÁI BİNH NĂM 2021
}

\author{
Ngô Văn Mạnh*, Bùi Thị Huyền Diệu*, Hà Ánh Nguyệt*
}

\section{TÓM TẮT}

Mục tiêu của nghiên cứu nhằm mô tả thực trạng và một số yếu tố liên quan đến sử dụng rượu bia ở nam sinh viên ngành y đa khoa tại trường Đại học $Y$ Dược Thái Bình năm 2021. Nghiên cứu mồ tả cắt ngang trên 598 nam sinh viên trường Đai hoc $Y$ Dước Thái Bình từ tháng 3/2021 đến tháng 6/2021 bằng bộ câu hỏi đã được chuẩn bị sẵn. Kết quả nghiên cứu cho thấy tỷ lệ nam sinh y đa khoa trường Đại học $Y$ Dược Thái Bình đang/đã từng sử dụng bia rượu khá cao (86,5\%). Sinh viên không sống cùng bố mẹ, hút thuốc lá và sinh viên năm giữa khóa hoc $(Y 3, Y 4)$ là các yếu tố liên quan tới sử dụng rượu bia của nam sinh viên. Cân tâp trung tăng cường tuyên truyền tác hại sử dụng rượu bia, xây dựng phong trào nói không với rượu bia, thuốc lá ở sinh viên đặc biệt các khối sinh viên năm giữa khóa học.

Từ khóa: rượu bia, sinh viên, yếu tố liên quan

\section{SUMMARY \\ THE SITUATION AND RELATED FACTORS TO ALCOHOL USING AMONG MALE GENERAL MEDICAL STUDENTS AT THAI BINH UNIVERSITY OF MEDICINE AND PHARMACY 2021}

A cross-sectional study on 598 students at Thai Binh University of Medicine and Pharmacy from 3/2021- 6/2021 was carried out to describe the situation and some related factors to alcohol using among male general medical students at Thai Binh University of Medicine and Pharmacy in 2021. The results showed that the percentage of male general medical using alcohol was high $(86.5 \%)$. Students who do not live with their parents, smoking and middle-year students (3nd year and 4nd year students) were factors that increase the risk of alcohol using among male students. It is necessary to focus on strengthening propaganda on the harmful effects of alcohol using, building a movement to say no to alcohol and tobacco among students, especially middle-year students.

Keywords: Alcohol, student, related factors

\section{I. ĐĂTT VẤN ĐỀ}

Tỷ lê sử dụng rượu bia ở sinh viên ở các nước trên thế giới đều khá cao như tại Mỹ theo Viện

\footnotetext{
*Trường Đại học Y Dược Thái Bình

Chịu trách nhiệm chính: Ngô Văn Mạnh

Email: manhsdh@gmail.com

Ngày nhận bài: 22.6.2021

Ngày phản biện khoa học: 18.8.2021

Ngày duyệt bài: 24.8.2021
}

Quốc gia về Lạm dụng Rượu và Nghiện rượu năm 2019 gân 53\% sinh viên đại học từ 18-22 tuổi đã uống rượu trong tháng qua [1], hay tại Tây Ban Nha có 47,6\% sinh viên là người nghiện rượu [2], 61\% sinh viên ở Anh dương tính với điểm AUDIT[3]. Tại Việt Nam theo điêu tra quốc gia về sức khỏe vị thành niên và thanh niên lân thứ 3 năm 2015 cho thấy tỷ lệ thanh niên từng say rượu có $41,7 \%$ trong độ tuổi từ 16 đến 19 và 58,1\% từ 20 đến 24 tuổi [4] hay tỷ lệ sinh viên uống rượu/bia tại Hà Nội (85.9\%), Huế $(84,5 \%)$ và Hồ Chí Minh (80,0\%)[5], 75,8\% sinh viên y đa khoa Hải Phòng đã từng uống rượu bia [6]. Thói quen uống rượu bia đăc biêt ở lứa tuổi thanh niên gây ảnh hưởng rất nhiêuu tới sức khỏe và xã hội. Theo WHO, rượu/bia là nguyên nhân trực tiếp của ít nhất 30 bệnh [7] và là nguyên nhân gián tiếp của trên 200 loại bệnh tật [8], là một trong 4 yếu tố nguy cơ hàng đâu của các bệnh không lây nhiễm liên quan các bệnh tim mạch, hệ tiêu hóa, suy giảm miễn dịch và đặc biệt là ung thư - các bệnh này chiếm 46\% số ca tử vong do hậu quả của sử dụng rượu bia trên toàn câu [9].

Tỉnh Thái Bình là một tỉnh có số lượng lớn sinh viên với hơn 15000 sinh viên trong đó trường Đại học $Y$ Dược Thái Bình có số sinh viên đông nhất với khoảng 7000 sinh viên, nhiều nhất là khối y đa khoa. Với mong muốn đưa ra được cái nhìn chung nhất về tỷ lệ sử dụng rượu bia và các yếu tố liên quan đến hành vi sử dụng rượu bia của nam sinh viên y đa khoa tại trường chúng tôi đã tiến hành nghiên cứu này.

\section{II. ĐỐI TƯợNG VÀ PHƯƠNG PHÁP NGHIÊN CỨU}

2.1 Đối tượng nghiên cứu. Đối tượng nghiên cứu là sinh viên nam ngành y đa khoa tại trường Đại học Y Dược Thái Bình.

Tiêu chuẩn lựa chọn: Là sinh viên nam hệ chính quy ngành y đa khoa đang học tại Trường ĐHYDTB, đồng ý tham gia nghiên cứu.

Tiêu chuân loại trư': Sinh viên hệ liên thông, sinh viên hệ chính quy các chuyên ngành khác y đa khoa, sinh viên từ chối tham gia nghiên cứu.

2.2 Địa điểm và thời gian nghiên cứu. Nghiên cứu được thực hiện tại trường Đại học Y Dược Thái Bình từ tháng 3 năm 2021 đến tháng 
6 năm 2021.

2.3 Thiết kế nghiên cứu. Nghiên cứu được tiến hành theo phương pháp mô tả cắt ngang.

2.4 Cỡ mâ̂u nghiên cứu. Áp dụng công thức tính cỡ mẫu so sánh 1 tỷ lệ:

$$
\mathrm{n}=\mathrm{Z}^{2}(1-\alpha / 2) \frac{p(1-p)}{d^{2}}
$$

Trong đó: $\mathrm{n}$ là số nam sinh viên y đa khoa cần nghiên cứu; $\mathrm{p}$ là tỷ lệ sinh viên y đa khoa đã từng sử dụng rượu bia lấy từ nghiên cứu tại ĐHYD Hải Phòng, $p=0,758$ [6]; d: Độ chính xác tuyệt đối (lấy $d=0,0035) ; a$ : Chọn mức ý nghĩa thống kê $95 \%$, có $a=0,05$. Thay vào công thức ta có $\mathrm{n}=575$. Thực tế chúng tôi đã điều tra 598 nam sinh viên y đa khoa.

2.5 Phương pháp chọn mẫu. Bằng phương pháp chọn mẫu ngẫu nhiển, mỗi khối chúng tôi sẽ lập danh sách các lớp, bốc thăm ngẫu nhiên chọn 4-5 lớp nghiên cứu. Tại mỗi lớp được chọn sẽ lấy toàn bộ sinh viên nam tình nguyện tham gia nghiên cứu.

2.6 Biến số nghiên cứu. Các biến số về nhân khẩu học của đối tượng: khối học, quốc tịch, thông tin về gia đình, học tập, cuộc sống, các mối quan hệ

Các biến số về thực trạng sinh viên nam uống rượu bia: tỷ lệ nam sinh viên sử dụng rượu bia, tần suất sử dụng,

Phương pháp thu thập thông tin. Các thông tin được thu thập qua bộ câu hỏi đã chuẩn bị sẵn được phát phiếu trực tiếp tới sinh viên Y1Y5 và phiếu online tới sinh viên Y6 (do dịch bệnh COVID-19). Bộ câu hỏi gồm các phần: thông tin chung về đối tượng nghiên cứu, các thông tin về thực trạng sử dụng và yếu tố liên quan.

2.8 Phương pháp xử lý số liệu. Số liệu được kiểm tra kỹ trước khi nhập, nhập bằng phần mềm Epidata 3.1 và phân tích bằng SPSS22.0. Các biến định lượng sẽ được trình bày bằng tỷ lệ \%, các biến liên tục được trình bày bằng trung bình và độ lệch chuẩn. Sử dụng mô hình hồi quy Logistic đớn biến và đa biến xác định các yếu tố liên quan đến sử dung rươu bia ở nam sinh y đa khoa. Các biến số trong mồ hình hồi quy đơn biến có $p<0,2$ sẽ được đưa vào mô hình hồi quy đa biến. Các yếu tố liên quan trong hồi quy đa biến được xác định với mức ý nghĩa $p<0,05$.

2.9 Đạo đức trong nghiên cứu. Nghiên cứu được sự chấp nhận của Ban Giám hiệu nhà trường, Phòng Nghiền cứu khoa học, Phòng Quản lý đào tạo đại học. Đề tài được thông qua hội đồng đạo đức theo quyết định số 823/QĐYDTB ngày $28 / 6 / 2021$. Sinh viên tự nguyện tham gia, các thông tin cá nhân được giứ bí mật và chỉ phục vụ cho nghiên cứu.

\section{KẾT QUẢ NGHIÊN CỨU}

Trong số 598 nam sinh viên tham gia nghiên cứu có $87 \%$ là người Việt Nam; tỷ lệ các khối học tham gia nghiên cứu tương đối đồng đều trong đó cao nhất là khối Y2 với 104 sinh viên tham gia và thấp nhất là khối Y4 với 97 sinh viên tham gia.

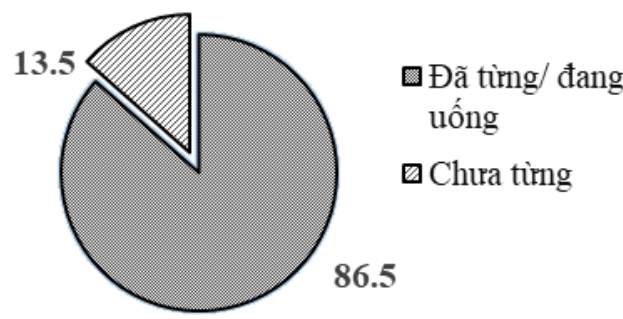

\section{Hình 1: Tỷ lệ nam sinh y đa khoa uống rướu bia}

Tỷ lệ nam sinh viên y đa khoa đã từng/ đang sử dụng rượu bia cao (86,5\%). Chỉ có $13,5 \%$ nam sinh viên y đa khoa chưa từng sử dụng rượu bia.

Bảng 1: Hồi quy đơn biến các yêu tô gia đình, bạn bè tới sử dụng rượu bia

\begin{tabular}{|c|c|c|c|c|c|c|}
\hline \multirow{3}{*}{\multicolumn{2}{|c|}{ Các yếu tố }} & \multicolumn{5}{|c|}{ Sử dụng rươu bia } \\
\hline & & \multicolumn{2}{|l|}{ Có } & \multicolumn{2}{|c|}{ Không } & \multirow[b]{2}{*}{$\mathbf{p}$} \\
\hline & & $n(n=517)$ & $\%$ & $n(n=81)$ & $\%$ & \\
\hline \multirow{4}{*}{$\begin{array}{c}\text { Số tiền bố mé cho hàng } \\
\text { tháng }\end{array}$} & 1-2 triêu & 156 & 87,6 & 22 & 12,4 & \multirow{4}{*}{$\begin{array}{c}p= \\
0,898\end{array}$} \\
\hline & 2-3 triệu & 208 & 86,3 & 33 & 13,7 & \\
\hline & 3-5 triệu & 107 & 86,3 & 17 & 13,7 & \\
\hline & $>5$ triều & 46 & 83,6 & 9 & 16,4 & \\
\hline \multirow{2}{*}{$\begin{array}{l}\text { Gia đình có người thường } \\
\text { xuyên uống rượu bia }\end{array}$} & Có & 226 & 89,7 & 26 & 10,3 & \multirow{2}{*}{$\begin{array}{c}p= \\
0,049\end{array}$} \\
\hline & Không & 291 & 84,1 & 55 & 15,9 & \\
\hline \multirow{5}{*}{ Mối quan hệ bạn bè } & Rất tốt & 180 & 85,3 & 31 & 14,7 & \multirow{5}{*}{$\begin{array}{c}p= \\
0,677\end{array}$} \\
\hline & Tốt & 213 & 87,7 & 30 & 12,3 & \\
\hline & Bình thường & 113 & 85,6 & 19 & 14,4 & \\
\hline & Không tốt & 8 & 100 & 0 & 0 & \\
\hline & Rất không tốt & 3 & 75 & 1 & 25 & \\
\hline
\end{tabular}




\begin{tabular}{|c|c|c|c|c|c|c|}
\hline \multirow{5}{*}{$\begin{array}{c}\text { Mối quan hế người yêu } \\
\text { (nếu có) }\end{array}$} & Rất tốt & 132 & 86,3 & 21 & 13,7 & \multirow{5}{*}{$\begin{array}{c}p= \\
0,653\end{array}$} \\
\hline & Tốt & 52 & 92,9 & 4 & 7,1 & \\
\hline & Bình thường & 12 & 85,7 & 2 & 14,3 & \\
\hline & Không tốt & 1 & 100 & 0 & 0 & \\
\hline & Rất không tốt & 4 & 100 & 0 & 0 & \\
\hline
\end{tabular}

Kết quả bảng trên cho thấy sinh viên trong gia đình có người thường xuyên uống rượu bia có khả năng sử dụng rượu bia cao hơn sinh viên trong gia đình không có người thường xuyên uống rượu bia với $p<0,05$. Không có sự khác biệt về sử dụng rượu bia với só tiền bố me cho hàng tháng, mối quan hệ bạn bè và mối quan hê với người yêu $(p>0,05)$.

Bảng 2: Hồi quy đơn biến các yếu tố bản thân đến sử dụng rượu bia

\begin{tabular}{|c|c|c|c|c|c|c|}
\hline \multirow{3}{*}{\multicolumn{2}{|c|}{ Đặc điểm }} & \multicolumn{5}{|c|}{ Sử dụng bia rượu } \\
\hline & & \multicolumn{2}{|l|}{ Có } & \multicolumn{2}{|c|}{ Không } & \multirow[b]{2}{*}{$\mathbf{p}$} \\
\hline & & $n(n=517)$ & $\%$ & $n(n=81)$ & $\%$ & \\
\hline \multirow{6}{*}{ Khối học } & Y1 & 79 & 78,2 & 22 & 21,8 & \multirow{6}{*}{$p=0,001$} \\
\hline & Y2 & 82 & 78,8 & 22 & 21,2 & \\
\hline & Y3 & 92 & 93,9 & 6 & 6,1 & \\
\hline & Y4 & 92 & 94,8 & 5 & 5,2 & \\
\hline & Y5 & 86 & 86 & 14 & 14 & \\
\hline & Y6 & 86 & 87,8 & 12 & 12,2 & \\
\hline \multirow{4}{*}{$\begin{array}{l}\text { Chương } \\
\text { trình học }\end{array}$} & Rất nặng & 89 & 83,2 & 18 & 16,8 & \multirow{4}{*}{$p=0,01$} \\
\hline & Nặng & 247 & 90,5 & 26 & 9,5 & \\
\hline & Bình thường & 172 & 84,3 & 32 & 15,7 & \\
\hline & Không nặng & 9 & 64,3 & 5 & 35,7 & \\
\hline \multirow{3}{*}{$\begin{array}{l}\text { Hút thuốc } \\
\text { lá }\end{array}$} & Không & 446 & 85,1 & 78 & 14,9 & \multirow{3}{*}{$p=0,011$} \\
\hline & Có & 28 & 93,3 & 2 & 6,7 & \\
\hline & Đã từng & 43 & 97,7 & 1 & 2,3 & \\
\hline \multirow{4}{*}{ Nơi sống } & ớ với bố mẹ & 35 & 76,1 & 11 & 23,9 & \multirow{4}{*}{$p=0,158$} \\
\hline & ớ nhà người thân & 13 & 92,9 & 1 & 7,1 & \\
\hline & Thuê trọ & 340 & 86,7 & 52 & 13,3 & \\
\hline & Ơ kí túc xá & 129 & 88,4 & 17 & 11,6 & \\
\hline \multirow{2}{*}{$\begin{array}{l}\text { Đi làm } \\
\text { thêm }\end{array}$} & Không & 370 & 85,1 & 65 & 14,9 & \multirow{2}{*}{$p=0,103$} \\
\hline & Có & 147 & 90,2 & 16 & 9,8 & \\
\hline
\end{tabular}

Kết quả bảng 2 cho thấy: Sinh viên $Y 3$ và Y4 biệt này có ý nghĩa thống kê với $p=0,01, X^{2}=$ có tỷ lệ sử dụng bia rượu cao hơn sinh viên các khối khác. Sự khác biệt này có ý nghĩa thống kê với $p=0,001$

Sinh viên cảm thấy chương trình học nặng/ rất nặng có tỷ lệ sử dụng rượu bia cao hơn so với sinh viên cảm thây chương trình học không nặng $(90,5 \% ; 83,2 \%$ so với $64,3 \%)$. Sự khác

11,426 .

Sinh viên có/đã từng hút thuốc có tỷ lệ sử dụng rượu bia cao hơn so với sinh viên chưa hút thuốc lá bao giờ. Sự khác biệt này có ý nghĩa thống kê với $p=0,011$ và $x 2=6,496$.

Không có sự khác biệt có ý nghĩa thống kê giữa tỷ lệ sử dụng bia rượu với nơi sinh sông của sinh viên và đia làm thêm tới việc sử dụng rượu bia.

Bảng 3: Hồi quy đa biến các yêu tố ảnh hưởng tới việc sử dụng rượu bia ( $n=598)$

\begin{tabular}{|c|c|c|c|c|}
\hline \multicolumn{2}{|c|}{ Các yếu tố } & OR & $\mathbf{9 5 \%}$ CI & P \\
\hline \multirow{4}{*}{ Khối học } & Y1 & 1 & & \\
\cline { 2 - 5 } & Y2 & 0,78 & $0,36-1,71$ & 0,549 \\
\cline { 2 - 5 } & Y3 & 3,50 & $1,26-9,73$ & 0,016 \\
\cline { 2 - 5 } & Y4 & 5,57 & $1,81-17,17$ & 0,003 \\
\cline { 2 - 5 } & Y5 & 1,29 & $0,57-2,93$ & 0,539 \\
\cline { 2 - 5 } & Y6 & 1,68 & $0,72-3,93$ & 0,227 \\
\hline \multirow{4}{*}{ Nơi sống } & Ơ với bố mè & 1 & & \\
\cline { 2 - 5 } & Ớ nhà họ hàng & 11,93 & $1,09-130,17$ & 0,042 \\
\cline { 2 - 5 } & Thuê trọ & 2,95 & $1,24-7,03$ & 0,014 \\
\cline { 2 - 5 } & Ớ kí túc xá & 3,66 & $1,33-10,01$ & 0,011 \\
\hline
\end{tabular}


TẠP CHÍ Y HỌC VIẸT NAM TẬP 506 - THÁNG 9 - SÓ 2 - 2021

\begin{tabular}{|c|c|c|c|c|}
\hline \multirow{3}{*}{ Chương trình học } & Không nặng & 1 & & \\
\cline { 2 - 5 } & Rất nặng & 2,17 & $0,45-10,54$ & 0,334 \\
\cline { 2 - 5 } & Nặng & 3,55 & $0,834-15,18$ & 0,086 \\
\cline { 2 - 5 } & Bình thường & 2,65 & $0,648-10,88$ & 0,175 \\
\hline \multirow{3}{*}{ Hút thuốc lá } & Không & 1 & & \\
\cline { 2 - 5 } & Có & 3,33 & $0,62-17,64$ & 0,157 \\
\cline { 2 - 5 } & Đã từng & 11,69 & $1,35-101,14$ & 0,025 \\
\hline \multirow{2}{*}{ Đi làm thêm } & Không & 1 & & \\
\cline { 2 - 5 } & Có & 1,61 & $0,84-3,08$ & 0,152 \\
\hline \multirow{2}{*}{$\begin{array}{c}\text { Gia đình có người thường } \\
\text { xuyên uống rượu bia }\end{array}$} & Không & 1 & & 0,21 \\
\cline { 2 - 5 } & Có & 1,440 & $0,81-2,54$ & 0,10 \\
\hline
\end{tabular}

Bảng 3 cho kết quả của hồi quy đa biến các yếu tố liên quan tới sử dụng rượu bia ở nam sinh y đa khoa là khối học, nơi sống hiện tại và hút thuốc lá. Về khối học: sinh viên năm y3 và y4 sử dụng rượu bia cao hơn gấp tương ứng 3,5 và 5,6 lần so với sinh viên năm nhất. Về nơi sinh ở: so với sinh viên sống cùng với bố mẹ, tình trạng sử dụng rượu bia của sinh viên sống cùng họ hàng cao gấp 11,93 lần; của sinh viên ở kí túc xá cao gấp 3,6 lần; sinh viên ở trọ cao gấp 2,95 lần, sinh viên đã từng hút thuốc lá có sử dụng rượu bia cao hơn so với sinh viên không hút thuốc lá gấp 11,7 lần.

\section{BÀN LUÂNN}

Về thực trang sử dụng rượu bia. Tỷ lệ nam sinh viên y đa khoa Đại học Y Dược Thái Bình đã từng sử dụng rượu bia cao $(86,5 \%)$, tỷ lệ này cao hơn sinh viên y đa khoa Đại học Y Dược Hải Phòng $(75,8 \%)$ [6] và tương đương với sinh viên tại các Đại học ở Hà Nội $(85,9 \%)$, Huế $(84,5 \%)$, Hồ Chí Minh (80\%) [5]. Sự khác biệt là do nghiên cứu tại Hải Phòng có đối tượng nghiên cứu là cả sinh viên nam và sinh viên nữa, và viếc sử dụng rượu bia ở nữ thường thấp hơn ở nam giới. Kết quả nghiên cứu của chúng tôi thấp hơn so với nghiên cứu tại các trường Đại học và Cao đẳng ở Huế $(92,7 \%)[10]$, có thể vì đối tượng trong nghiên cứu này là cả sinh viên Đại học và Cao đẳng khác ngành y đặc biệt là sinh viên Cao đẳng thì thường khối lượng học ít hơn, nhiêuu thời gian rảnh tụ tập ăn uống hơn sinh viên trường Đại học Y nên tỷ lệ sử dụng rượu bia cao hơn.

Về yếu tố liên quan tới sử dụng rượu bia. Phân tích hồi quy đa biến cho kểt quả, các yếu tố liên quan trực tiếp đến sử dụng rượu bia ở nam sinh y đa khoa bao gồm: Khối học, nơi sống hiện tại và yếu tố hút thuốc lá.

Một yếu tố quan trọng liên quan tới việc sử dụng rượu bia của nam sinh là nơi sống của họ. Những sinh viên không ở cùng với bố mẹ có khả năng sử dụng rượu bia cao hơn. Cụ thể sinh viên sống cùng người thân cao gấp 11,93 lần; ở kí túc xá cao gấp 3,6 lần; ở trọ cao gấp 2,95 lần. Điều này có thể lý giải sinh viên ở kí túc xá và ở trọ ít bị sự giám sát từ gia đình, thoải mái hơn trong tiếp cận sử dụng rượu bia; còn sinh viên ở với người thân tuy có sự giám sát của người lớn nhưng vẫn thường thoải mái hơn so với bố mẹ, đồng thời tiền sinh hoạt dư thừa khả năng cao hơn do ít chi phí sinh hoạt dẫn đến tăng sử dụng rượu bia hơn. Kết quả này của chúng tôi khá tướng đồng với phát hiện của nghiên cứu tại sinh viên y ở Pháp và các trường ở Huế [10].

Phân tích đa biến cho thấy sinh viên năm Y3 và Y4 sử dụng rượu bia cao hơn tương ứng 3,5 và 5,6 lần so với sinh viên Y1. Nguyên nhân có thể do sinh viên hai khối này nằm ở giai đoạn giữa đã quen với việc học đại học trường $y$, ít bị gia đình quản lý hớn và có nhiều thời gian rảnh hơn so với sinh viên năm cuối nên tỷ lệ sử dụng rượ bia cao hơn.

Trong kết quả của hồi quy đa biến thì việc sinh viên từng sử dụng thuốc lá cũng là yếu tố liên quan tới sử dụng rượu bia ở nam sinh viên. Sinh viên đã từng hút thuốc lá có sử dụng rượu bia cao hơn so với sinh viên không hút thuốc lá gấp 11,7 lần. Kết quả này tương đồng với nghiên cứu tại sinh viên y trường Đại học Paris VII, hay tại sinh viên trường Đại học Romania. Nguyên nhân có thể do các quán bán rượu bia thường kèm theo thuốc lá do đó việc sử dụng rượu bia và thuốc lá có thể dễ dàng đồng thời những người đã hút thuốc lá thì thường hay có những thói quen sống không lành mạnh khác trong đó có sử dụng rượu bia.

\section{KẾT LUẬN}

Tỷ lệ nam sinh y đa khoa trường Đại học $Y$ Dược Thái Bình đang/đã từng sử dụng bia rượu là khá cao (86,5\%). Sinh viên không sống cùng bố me, hút thuốc là và sinh viên năm giữa khóa học $(Y 3, Y 4)$ là các yếu tố liên quan tới sử dụng rượu bia của nam sinh viên. Cần tập trung tăng cường tuyên truyền tác hại sử dụng rượu bia, xây dựng phong trào nói không với rượu bia, 
thuốc lá ở sinh viên đặc biệt các khối sinh viên năm giữa khóa học

\section{TÀI LIỆU THAM KHẢO}

1. SAMHSA, Center for Behavioral Statistics and Quality. National Survey on Drug Use and Health, 2018 and 2019. Table 6.21B-Types of Illicit Drug, Tobacco Product, and Alcohol Use in Past Month among Persons Aged 18 to 22 .

2. Salas-Gomez $D$, Fernandez-Gorgojo $M$, Pozueta A, et al. Binge Drinking in Young University Students Is Associated with Alterations in Executive Functions Related to Their Starting Age. PLoS One. 2016; 11(11): e0166834.

3. Heather $N$, Partington $S$, Partington $E$, et al. Alcohol use disorders and hazardous drinking among undergraduates at English universities. Alcohol Alcohol. 2011; 46(3): 270.

4. UNFPA. Báo cáo quốc gia về thanh niên Viêt Nam. 2015; tr 52.

5. Phạm Bích Diệp. Bối cảnh uông rượu, bia của sinhi viên Việt Nam. Tạp chí Y học dự phòng. 2015; 6 (166): 470 .
6. Lê Trận Tuấn Anh, Nguyễn Thị Minh Ngọc, Nguyễn Thị Thanh Ngân. Kiến thức, thái độ hành vi uống rươu bia của sinh viên đa khoa hế dài hạn trường Đ̇ại học $Y$ Dược Hải Phòng năm 2015. Tap chí Y họ dư phòng. 2015; 11(171):29.

7. WHO. International Classification of Diseases and Related Health Problems, 10th Revision (version for 2007) Geneva, Switzerland. 2007.

8. WHO. Alcohol - September 2018. Truy câp ngày 01/3/2021. https://www.who.int/news-room/factsheets/detail/alcohol

9. Dương Hải. Uống 1 lon bia/ngày cũng tăng nguy cơ mắc ung thư, vậy mà người Việt "không say, không về". Báo Sức khỏe và đời sống. 2019. Truy cập 01/03/2021. https://suckhoedoisong.vn/uong1-lon-bia-ngay-cung-tang-nguy-co-mac-ung-thuvay-ma-nguoi-viet-khong-say-khong-ve169158054.htm

10. Phan Văn Sang, Hồ Thị Thùy, Trân Xuân An. Thực trạng lạm dụng rượu bia và các yếu tố liên quản của sinhi viên tại một số trường Đại học và Cao đẳng ở thành phố Huễ năm 2016. Tạp chí Y học dự phòng. 2017; 27(8):366-373.

\section{MộT SỐ YẾU TỐ LIÊN QUAN ĐẾN KẾT QUẢ ĐIỀU TRI NHIỄM KHUẨN HÔ HẤP CẤP TÍNH TAI KHOA KHÁM VÀ ĐIỀU TRI 24 GIỜ, BÊ̂NH VIỆN NHI TRUNG ƯO'NG.}

\section{TÓM TẮT}

Mục tiêu: Tìm hiểu môt số yếu tố liên quan đến kết quả điều trị nhiễm khuẩn hô hấp cấp tính tại Khoa khám và điêu trị 24 giờ, Bệnh viện Nhi Trung ương. Đô̂́i tượng: Trẻ từ 2 tháng đến dưới 60 tháng tuổi, diễn biển cấp tính dưới 7 ngày từ khi khởi phát bệnh được khám và điều trị nội trú tại khoa. Phương pháp nghiên cứu: Nghiên cứu mô tả tiến cứu. Kết quả: Nghiên cứu trên 203 bệnh nhân: tỷ lệ BN nam/ nữ là $1,9 / 1$, tuổi trung bình là $17,1 \pm 12,1$ (tháng), chủ yếu trên 12 tháng tuổi. BN nhập viện do NKHHDCT (76,9\%), gấp 3,3 lần số BN nhập viện do NKHHTCT, viêm phế quản phổi $(38,9 \%)$ chiểm tỷ lê cao nhất. BN ra viện tại khoa $24 \mathrm{~h}$ chiếm $84,7 \%$, tỷ lệ BN nặng lên cần chuyển khoa chiếm $15,3 \%$, không có bệnh nhân tử vong hoặc xin về. Không có sự khác biệt về kết quả điều tri NKHHCT ở hai giới nam và nữ, giữa nhóm trên và dưới 12 tháng, giá trị bạch câu, $C R P$, kết quả nuôi cấy dịch ty hâu, nhiếm RSVi. Thời gian nằm viện trung vị của nhóm NKHHTCT ngắn hơn NKHHDĆT. Kết luân: Trẻ nam găp nhiều hơn nữ, chủ yếu là nhóm trền 12 tháng tuổi, viêm đường hô hấp dưới và VPQP

*Bệnh viện Nhi trung ương

Chịu trách nhiệm chính: Pham Ngọc Toàn

Email: ngoctoancard@yahoo.com

Ngày nhận bài: 21.6.2021

Ngày phản biên khoa họ: 16.8.2021

Ngày duyệt bài: 24.8.2021
Phạm Ngọc Toàn*, Lã Thị Bích Hồng*

chiếm phần lớn. Không có sự khác biệt về kết quả điều trị liên quan tới độ tuổi, giới tính, số lượng bach cầu, CRP, kết quả nuôi cấy DTH, nhiễm RSV. Thời gian nằm viên của NKHHTCT ngắn hơn so với NKHHDCT

Tư khóa: Nhiễm khuẩn hô hấp trên và dưới, điều trị

\section{SUMMARY}

SOME FACTORS RELATED TO THE RESULTS OF TREATMENT OF ACUTE RESPIRATORY

TRACT INFECTIONS AT THE 24-HOUR EXAMINATION AND TREATMENT DEPARTMENT, NATIONAL CHILDREN'S HOSPITAL

Objective: To find out some factors related to the results of treatment of acute respiratory infections at the 24-hour examination and treatment department, National Children's Hospital. Subjects: Children from 2 months to less than 60 months old, with acute period less than 7 days, were examined and treated inpatient at the department. Research Methods: A prospective descriptive study. Results: A study on 203 patients the boy/girl ratio was $1.9 / 1$, the mean age was $17.1 \pm 12.1$ (months), mainly over 12 : months old. Patients hospitalized due to acute lower respiratory tract infections $(76.9 \%), 3.3$ times higher than the number of patients hospitalized due to acute upper respiratory tract infections, bronchopneumonia $(38.9 \%)$ accounted for the highest rate. Patients were discharged from the $24 \mathrm{~h}$ ward, accounting for $84.7 \%$, the rate of patients getting worse and needing to be transferred to high level accounted for $15.3 \%$, no 